\title{
Micromarketing of University Library Information Service under Mobile Social Network Platform
}

\author{
Zhang Hanyu \\ Xi'an Aeronautical Polytechnic Institute, Library, Xi'an, Shaanxi, 710089
}

Keywords: microblog; mobile social network; library information service

\begin{abstract}
At present, mobile social networks, represented by microblog applications, have received widespread attention and recognition from the library community. This paper analyzes difficulties and opportunities brought about by the technological changes in the era of mobile Internet to library information services from multiple perspectives. In combination with the innovative practice of national library microblog information services, this paper discusses the development direction and problems of library information services based on mobile social networks.
\end{abstract}

\section{Introduction}

With the increasing trend of Internet mobilization and socialization, mobile terminals such as smart phones and PADs are widely used. As a representative platform for mobile social networks, microblog has become an important channel for information release, search, acquisition and dissemination. There are many libraries that have applied microblogging to library work. According to the literature survey, most of the library's microblog service practice and research pages only provide basic services such as publicity announcements, internal and external communication, and information transfer, and few libraries implement practical deep information services (extended services) based on microblogs. [1-4]. Today, mobile social networks have demonstrated a growing trend of development. While changing people's lifestyle, they also have a major impact on library information services. In the new situation, the library must be repositioned to use mobile social networks such as Weibo to improve its service quality, expand service content, and achieve effective integration of library information services and social networks.

\section{Research Status of Mobile Social Networks}

As a research hotspot in the current library and information field, domestic libraries conduct a series of theoretical and practical researches on information services based on mobile social networks. Lou Xiangying and others focused on analyzing the characteristics of mobile social networking and provided guiding strategies for the application of mobile social networks in libraries [5]; Zhang Jian et al pointed out the development of disciplines by introducing the practice of Tsinghua University library in mobile social networks. The problems that need to be paid attention to in the process of knowledge mobile service provide reference for library knowledge mobile service [6]; Zhao Yaxin investigates the library user needs in microenvironment, and points out that library microservices should combine the characteristics of user needs and focus on mobile social networks application [7]. It can be seen that while domestic scholars have conducted research on mobile social networks in library information services, there are not many practical studies that combine specific service cases. Therefore, this paper mainly discusses the practical application of the national library through use of social media represented by Weibo.

\section{Development Status and Predicament of Mobile Digital Library}

The mobile digital library combines wireless communication networks with digital library systems, using smartphones with rapidly growing penetration as mobile digital reading terminals and supplementing and extending digital library services in the era of mobile internet. In the era of 
mobile Internet, various mobile terminals have become an important channel for public access to information. To achieve deep-level application services through mobile digital libraries, it is necessary to meet the needs of users for quick, convenient, and low-cost access to original text information anytime and anywhere; to achieve this goal, it is necessary to completely resolve the content and copyright of mobile digital libraries under the construction of an information service system concerning four problems in technology, readership and readership [8-9]. At present, the number of arrivals and home page visits of libraries in various countries is clearly declining. It is precisely due to the fact that the status quo of library-based work processes and multiple information service methods centered on books (various forms) cannot be combined passively to meet the reader's urgent need for diversified information.

Faced with the ever-changing needs of readers for information acquisition, the library mobile information service cannot simply transplant the web-based digital library's traditional service content to the mobile terminal. Instead, it should actively explore at the technical level and conduct information needs analysis and information services through microblogs. Innovate in ways to create a service platform with media and interest communities, use a variety of information types and timely communication methods to form a continuous attraction for users, improve user stickiness, and embark on the dilemma of constant loss of users.

\section{Objects and Requirements of National Mobile Library Information Service in Mobile Internet Era}

Through research on the composition of national library users and their needs, it has been found that the needs of users, especially core users, use the Internet to remotely access literature or information that are not fully met, and it is also stated from the side that the library still needs to strengthen its propaganda for users. Users are familiar with the information services provided by the library. In the information age, thanks to the rapid development of digital technologies for Internet and literature resources, library users can access library collection resources through the Internet. The innovation of social services represented by Weibo applications will help integrate information services into the social life of users.

Scientific and technological progress improves library users' work and learning efficiency, but it also greatly reduces chances and time for librarians and users. Librarians are urged to pay more attention to relying on digitization and networking to improve the utilization rate of documents and ignore the diversified information needs of users. The mobile social network not only refers to the user network social experience on the mobile device platform or the mobile terminal, but also includes a mobile lifestyle where people share attention, interests, emotions, status, and activities anytime and anywhere. Before conducting a mobile social network, the library first needs to analyze mobile social networking applications including content sharing, contact interaction, and contextawareness experiences, and deeply understands that mobile social networks are not complementary to traditional desktop online social networks. Instead, it will integrate mobile information services into people's social life; then, using information analysis, sociology, and even psychology as a guide, users' reality in the user circle recognition, influence calculation, and information communication habits analysis the various needs of the world and online virtual communities; Finally, enhance the linkage and interaction between librarians and users in the real world and the virtual world, provide users with integrated information services.

\section{Conclusion}

Different from traditional social network users, Weibo users have significant mobility characteristics and have a stronger demand for information, and the information will also show specific, accurate and personalized characteristics. With the in-depth development of mobile social network information services, the library will also face an explosion of user information flow and filtering of bad information, opening up of user consultation information and privacy protection of document transmission, different levels of knowledge sharing and interest sharing of different users, 
and long-term microblog information. Accumulation is not easy to classify and other issues remain. Properly addressing these issues will help libraries use mobile social networks to provide more users with information that meets their immediate needs while constantly pursuing the shortest possible service time limit.

\section{References}

[1] Chen Lin. Research on the Current Situation of Microblogging Application in Domestic Libraries [J].Researches in Library Science, 2011(24):30-33, 5.

[2] Liu Ying. Exploration of University Library's Use of Microblog to Expand Reader Service [J]. Library Work Study, 2012(6):121-124.

[3] Li Chao. An Analysis of the Current Status of Domestic Microblogging Services for Libraries in China [J]. Library Magazine, 2012, 31(2): 24-28.

[4] Cong Kong. Research on the Status Quo of Microblogging Service in Domestic Libraries Taking Sina Weibo as an Example [J]. Journal of Library and Information Sciences in Agriculture, 2011, 23(12):204-208.

[5] Lou Xiangying, Gao Chunling. Application of Mobile Social Network in Libraries [J]. Library Magazine, 2013, 32(12): 29-32.

[6] Zhang Hao, Dou Tianfang, Zhang Chengyu, et al. Exploration of Mobile Service Extension in University Libraries Based on Subject Knowledge[J]. Knowledge Management Forum, 2014(3):1318.

[7] Zhao Yaxin. Investigation of Library User Requirements in Micro-information Environment [J]. Library and Information Service, 2013, 57(8):17-21, 39.

[8] Zhang Weirong, Jia Aixia. The Application of Mobile Phone in Mobile Digital Library [J].SciTech Information Development \& Economy, 2008(22):3-6.

[9] Lu Chengzhao. Smartphone Library: New Development of Mobile Library Based on 3G [J]. Library Science Research, 2010(2):96-98. 